\title{
BMJ Open Exploring the impact, response and preparedness to water-related natural disasters in the Barisal division of Bangladesh: a mixed methods study
}

\author{
Jagnoor Jagnoor, ${ }^{\odot 1,2,3}$ Aminur Rahman, ${ }^{4}$ Patricia Cullen, ${ }^{1}$ \\ Fazlul Kader Chowdhury, ${ }^{4}$ Caroline Lukaszyk, ${ }^{1}$ Kamran ul Baset, ${ }^{4}$ Rebecca Ivers ${ }^{2,5}$
}

To cite: Jagnoor J, Rahman A Cullen $\mathrm{P}$, et al. Exploring the impact, response and preparedness to water-related natural disasters in the Barisal division of Bangladesh: a mixed methods study. BMJ Open 2019;9:e026459. doi:10.1136/ bmjopen-2018-026459

- Prepublication history and additional material for this paper are available online. To view these files, please visit the journal online (http://dx.doi. org/10.1136/bmjopen-2018026459).

Received 10 September 2018 Revised 17 January 2019 Accepted 29 January 2019

Check for updates

(C) Author(s) (or their employer(s)) 2019. Re-use permitted under CC BY-NC. No commercial re-use. See rights and permissions. Published by BMJ.

${ }^{1}$ Injury Division, The George Institute for Global Health,

Sydney, Australia

${ }^{2}$ School of Public Health and Community Medicine, University of New South Wales, Sydney, New South Wales, Australia ${ }^{3}$ The George Institute for Global Health, University of New South Wales, New Delhi, New Delhi, India

${ }^{4}$ International Drowning Research Centre, Centre for Injury Prevention and Research Bangladesh, Dhaka, Bangladesh ${ }^{5}$ Flinders University, Adelaide, South Australia, Australia

Correspondence to

Dr Jagnoor Jagnoor;

jjagnoor@georgeinstitute.org.au

\section{ABSTRACT}

Objectives To investigate the impact of natural disasters on communities in the Barisal division of Bangladesh, exploring community approaches to disaster preparedness and mitigation.

Setting Communities in all districts of the Barisal division of Bangladesh.

Participants Quantitative data were collected through a cross-sectional household survey ( $\mathrm{n}=9263$ households; $\mathrm{n}=38981$ individuals). Qualitative data were collected through in-depth interviews $(n=7)$ and focus group discussions $(n=23)$ with key informants.

Outcome measures Quantitative research recorded features of natural disaster events from the previous 5 years, documenting risk factors that increase vulnerability to disaster, use of disaster warning systems and evacuation processes. Qualitative research investigated disaster risk perceptions, experiences during and following disaster, and disaster preparedness practices.

Results The survey response rate was $94.7 \%$. Exposure to disaster in the last 5 years was high (82\%) with flooding and cyclones considered the greatest threats. Awareness of evacuation processes was low; and only $19 \%$ of respondents evacuated their homes at the time of disaster. Drowning during disaster was the primary concern (87\%), followed by debt, livestock and crop loss (78\%). The qualitative findings indicated prevailing fatalistic perceptions towards natural disasters among community. The consequences of disasters included significant loss of livelihoods and exposure to infections due to poor sanitation. There was also insufficient support for the most vulnerable, particularly women, children and the elderly. Although several community preparedness and practices existed, there was a lack of response to early warning systems. Barriers to disaster response and resilience included financial insecurities, loss of livelihoods and cultural concerns regarding women's privacy.

Conclusions Critical to achieving disaster resilience is increased government investment in infrastructure and systems-level responses that empower communities. Further research can support this by addressing community challenges to promoting disaster resilience and how to leverage existing community strengths to implement locally owned solutions.
Strengths and limitations of this study

- To our knowledge, this is the first large scale study reporting on context of disasters, using mixed methods from a low-income and middle-income country (LMIC).

- This study was conducted in an LMIC prone to water-related disasters and the results may not be generalisable to other LMIC settings; however, the qualitative focus group discussions and in-depth interviews spanned a diverse array of participants and yielded rich data that greatly contextualised the cross-sectional survey.

- Consultations with government representatives are likely to have provided additional insight into existing government initiatives targeted at disaster preparedness and response.

\section{INTRODUCTION}

Climate-related disasters significantly impact the health, personal security and livelihood of individuals, communities and societies. Between 1998 and 2017, climate-related disasters were the cause of over 1.3 million deaths worldwide, and resulted in a further 4.4 billion people sustaining injuries, becoming homeless, displaced or requiring emergency assistance. ${ }^{1}$ The impacts of climate-related disaster are most severely experienced by those living in low-income and middle-income countries (LMICs) who have a higher dependence on natural resources and who are exposed to higher rates of socioeconomic disadvantage which prevents the development of coping capacity. ${ }^{2}$ One such country is Bangladesh, which is highly prone to flooding due to the annual monsoon rainfalls and extensive low lying floodplains that cover an estimated $80 \%$ of the densely populated country. ${ }^{3}$ With a population of over 165 million, it is estimated that more than two-thirds of people in Bangladesh live in regions at risk of floods and one quarter live in regions at risk 
of cyclone. ${ }^{4}$ The consequences of flooding in this context include the threat of diarrhoeal disease, lack of access to safe drinking water, loss of housing, livestock, crops, livelihood activities and drowning in floodwaters. ${ }^{34}$ Additionally, tropical cyclones are an annual occurrence, which directly contribute to flooding and in turn, drowning-related mortality and morbidity. ${ }^{4}$

There is an increasing global focus on strengthening disaster risk reduction through improved surveillance, information exchange, early warning systems and capacity building in disaster prone countries. From 2005 to 2015, global governments committed to implementing the Hyogo Framework for Action as a guideline for reducing disaster risk through resilience building at both the national and local levels. ${ }^{5}$ More recently, the Sendai Framework for Disaster Risk Reduction 2015-2030 was adopted by the United Nations member states in March 2015. The framework represents the next phase of targets and priorities globally, recognising the threat that climate change and disaster risk pose to achieving the sustainable development goals. ${ }^{6}$

The risk of natural disasters in Bangladesh is projected to increase with changing weather patterns associated with extreme vulnerability to climate change. ${ }^{3478}$ In the face of growing climate uncertainty, there is an urgent need to understand disaster practices and promote community disaster resilience. In 1991, Cyclone Gorky struck Bangladesh, claiming the lives of 138000 people. This event has spurred improvements in disaster warning systems and increased shelter uptake over the last 20 years; ${ }^{49}$ however, there remain considerable challenges in fostering disaster resilience at all levels. Currently, there is only fragmented information available on the consequences of natural disasters in Bangladesh and on existing practices associated with disaster mitigation. Through identifying gaps in current processes, targeted interventions may be implemented to strengthen existing approaches to disaster preparedness, with a focus on disaster risk reduction. Therefore, this study aims to investigate the impact of natural disasters on communities in the Barisal division of Bangladesh, exploring community disaster preparedness, responses to disaster at time of onset and health seeking behaviours following disaster events. Given the complex nature of this topic, a mixed methods approach was used to facilitate a comprehensive understanding of the impact of and practices that surround natural disasters in the Bangladesh context. This information is anticipated to contribute to future disaster resilience planning activities for the region.

\section{METHODS}

\section{Study setting}

The Barisal division is located in south central Bangladesh and comprises six districts and 39 subdistricts (figure 1). Crossed by numerous rivers, it is highly exposed to flooding due to annual monsoon rains and low-lying flood plains.
Figure 1 Map of the Barisal division of Bangladesh (Source: Royal National Lifeboat Institution, UK. Figure used with permission of the copyright holders).

\section{Study design}

The study used a concurrent mixed methods approach, triangulating cross-sectional household survey data with qualitative in-depth interviews and focus group discussions. Both quantitative and qualitative data were collected as baseline measures of a larger intervention study which aims to significantly reduce drowning rates in the Barisal division by 2020. As no previous literature was available regarding Knowledge, Attitude and Practices for disaster resilience from LMICs, a mixed methods approach was used to gain an in-depth understanding of behaviours, perceptions and responses to disaster.

\section{MATERIALS AND DATA COLLECTION Quantitative}

The survey was conducted September 2016-February 2017 (over a 6-month period), using a multistage cluster sampling method. The survey was conducted as a baseline measure for a larger intervention-based drowning reduction project to be implemented in selected districts of the Barisal division from 2017 to 2020. The sample size $(n=385000)$ was chosen based on the sample required for the previous Bangladesh Health and Injury Survey, ${ }^{10}$ with the margins of $95 \%$ CIs providing evidence of sufficient sample size.

Briefly, the sample selected represents all districts within the division. Upazilas from the districts were randomly selected to be included in the project, with further random selection used to identify villages/sites within each upazila for data collection. Within each village, households were selecting using the EPI sampling method. ${ }^{11}$ The disaster subsample $(10 \%, \mathrm{n}=38981)$ was selected from the main sampling frame by selecting every household with computer generated ID ending in ' 0 . Questions presented to participants within the disaster subsample were primarily focused on postdisaster practices at the time of disaster to assess the acceptability, reliability and coverage of existing warning systems. The survey questions are available in online supplementary file 1. 
Trained data collectors, local to each participating community, used pretested structured questionnaires to collect information from household heads, mothers or any adult above 18 years through face-to-face interviews. One adult was interviewed per household, who reported data on behalf of all household members. An electronic data capture system (REDCap) was used on tablets for data collection. ${ }^{12}$ To ensure data quality and accuracy, trained supervisors observed and checked $10 \%$ collected data and reinterviewed $2 \%$ of households. The survey consisted of questions on knowledge, attitudes and perceptions/practices for community drowning and disaster risk, and about experiences of natural disaster in the previous 5 years. Data were collected on demographic characteristics, and on socioeconomic status using an index developed for the 2014 Bangladesh Demographic and Health Survey. ${ }^{13}$

\section{Qualitative}

Purposive sampling was used to identify key informants from the community for in-depth interviews and focus group discussions. For inclusion in the study, participants were required to have resided within Barisal for at least 6 months prior to data collection. Separate male and female discussion groups were arranged to align with cultural practices. The interviews and focus group discussions were semistructured and conducted by trained research assistants in community locations that were acceptable and accessible to participants. Consent was obtained prior to commencing data collection; interviews lasted between 40 and $60 \mathrm{~min}$, while focus group discussions lasted between 1 and 1.5 hours. The interview and focus group discussion guides included questions related to (1) disaster risk perceptions; (2) experiences of natural disaster and (3) disaster preparedness practices. Questions aimed to identify examples of good practice in disaster preparedness from community settings to include in future comprehensive disaster resilience planning activities. Further, questions aimed to explore gaps in current disaster preparation, management and relief processes that have been potentially addressed through targeted interventions. Interview and focus group discussion guides are available in online supplementary file 2.

Interviews and focus group discussions were conducted in Bengali, audiorecorded, translated and transcribed in English. To minimise data loss, interviews were jointly translated and transcribed by the interviewing researcher and the translator, and a member of the research team checked the translated transcripts for accuracy. Interviews ceased when saturation of meaning was considered to have occurred.

\section{ANALYSIS \\ Quantitative \\ Descriptive analysis (counts and percentages) was performed on variables relating to disaster knowledge,}

attitudes and behaviour variables. All data were analysed using SAS V.9.4 with SAS/STAT V.14.2.

\section{Qualitative}

Transcripts were imported into NVivo qualitative data analysis software (QSR International V.11, 2015). Content analysis was applied to the transcripts whereby overarching themes were initially developed followed by inductive thematic coding of the data. NVivo was used to arrange the text according to codes and manage the codes in the interpretive phase. Two researchers independently conducted the coding and arrived at consensus on the analyses.

\section{Patient and public involvement}

Drowning was identified as a priority health issue through the 2014 Bangladesh Demographic and Health Survey, which collected data from 18000 residential households nationwide. ${ }^{13}$ Data collection instruments for this present study were developed by the project team in alignment with Bangladesh Health and Injury Survey findings,${ }^{10}$ designed to investigate notable drowning-related outcomes in greater depth. All data collection tools were trialled with end users prior to their use in this study, investigating their readability, clarity and the relevance of questions included. Study results were triangulated among key informants and consultations and were used to inform the development of pilot interventions for improving water safety and reducing drowning in community settings in Bangladesh.

\section{RESULTS}

\section{Quantitative results}

A total of 95124 households were visited, of which 92616 household representatives were available for completing the survey (this corresponded to data gathered for $\mathrm{n}=385127$ individuals; response rate $94.7 \%$ ). There was an average household size of 4.2 members. For the disaster toll subsample ( $\mathrm{n}=9263$ households visited, data collected for $\mathrm{n}=38981$ individuals) was completed. There were no meaningful differences in the sociodemographic characteristics of the full household survey sample and the disaster subsample (table 1). All following results reported are for the survey disaster subsample. These findings are reported in line with the Consolidated Criteria for Reporting Qualitative Research statement, which supports transparency in reporting qualitative research (online supplementary file 3).

\section{Types of disaster}

Using a recall period of 5 years, the most common natural disaster events experienced by respondents were flooding/flash flooding (43\%) and cyclones (35\%). The majority of respondents (82\%) reported experiencing one or more natural disasters in the previous 5 years. Of these respondents, two-thirds believed flooding/flash 
Open access

Table 1 Sociodemographics of the full household survey and disaster survey subsample

Disaster subsample, $\mathrm{n}=\mathbf{3 8} 981$

(95\% Cl)

Full household sample, n=385 127

$(95 \% \mathrm{Cl})$

Age (years)
Infant
$1-4$
$5-9$
$10-14$
$15-17$
$18-24$
$25-39$
$40-59$
$60+$
Sex
Male

Male

$2.0 \%(1.8$ to 2.2$)$

$2.0 \%$ (1.9 to 2.0$)$

$8.1 \%(7.8$ to 8.5$)$

$8.2 \%$ (8.0 to 8.3$)$

$11.0 \%(10.7$ to 11.4$)$

$10.7 \%$ (10.5 to 10.8$)$

$10.8 \%$ (10.5 to 11.1$)$

$10.7 \%$ (10.6 to 10.9$)$

$5.9 \%$ (5.6 to 6.2$)$

$6.0 \%$ (5.9 to 6.1$)$

$13.6 \%$ (13.1 to 14.1$)$

$14.0 \%$ (13.8 to 14.2$)$

$24.6 \%$ (24.0 to 25.2 )

$24.1 \%$ (23.7 to 24.4$)$

$17.1 \%$ (16.6 to 17.5$)$

$17.5 \%$ ( 17.3 to 17.7$)$

$6.8 \%$ (6.4 to 7.1$)$

$6.9 \%$ (6.7 to 7.1$)$

Female

$49.1 \%(48.5$ to 49.8$)$

$49.2 \%$ (48.8 to 49.5$)$

$50.9 \%(50.2$ to 51.5$)$

$50.8 \%$ (50.5 to 51.2$)$

Marital status

Mever married

Divorced

$50.4 \%$ (49.9 to 50.9 )

$50.6 \%$ (50.3 to 51.0 )

$45.7 \%$ (45.2 to 46.2 )

$45.3 \%$ (45.1 to 45.6 )

Widow/widower

$0.3 \%$ (0.2 to 0.4$)$

$0.3 \%$ (0.3 to 0.4 )

$3.4 \%$ (3.2 to 3.7 )

$3.5 \%$ (3.4 to 3.7 )

Separated

$0.2 \%$ (0.1 to 0.2$)$

$0.2 \%$ (0.2 to 0.2$)$

Type of family

Nuclear family

$67.5 \%$ (65.4 to 69.7$)$

$66.6 \%$ (64.8 to 68.3$)$

Extended family

$32.5 \%$ (30.3 to 34.6 )

$33.4 \%$ (31.7 to 35.2 )

Family size

5 or less persons

$78.6 \%$ (77.0 to 80.3$)$

$78.6 \%$ (77.4 to 79.8 )

More than 5 persons

$21.4 \%$ (19.7 to 23.0 )

$21.4 \%$ (20.2 to 22.6 )

Education completed

Not applicable
1-5years
$6-8$ years
$9-12$ years

$16.3 \%$ (15.4 to 17.3$)$

$16.2 \%$ (15.2 to 17.1$)$

$39.9 \%$ (38.9 to 40.9 )

$39.8 \%$ (39.0 to 40.7 )

$17.9 \%$ (17.3 to 18.5$)$

$17.6 \%$ (17.2 to 18.1$)$

$16.4 \%$ (15.6 to 17.3 )

$16.6 \%$ (16.0 to 17.2 )

13-17 years

$3.7 \%$ (3.3 to 4.0 )

$3.7 \%$ (3.4 to 3.9 )

None

$5.7 \%$ (4.8 to 6.7$)$

$6.1 \%$ (5.2 to 7.0$)$

Maternal education

1-5years

6-8years

$47.9 \%$ (46.4 to 49.5$)$

$46.3 \%$ (45.1 to 47.5$)$

$20.6 \%$ (19.3 to 21.8 )

$20.5 \%$ (19.5 to 21.4$)$

$13.2 \%$ (12.1 to 14.4$)$

$14.2 \%$ (13.5 to 15.0$)$

13-17years

$1.5 \%$ (1.2 to 1.8$)$

$1.4 \%$ (1.3 to 1.6$)$

None

$16.7 \%$ (15.3 to 18.2$)$

$17.6 \%$ (16.4 to 18.8$)$

Monthly income (US\$/month)

\begin{tabular}{lcc}
$<80$ & $9.0 \%(7.9$ to 10.2$)$ & $9.2 \%(8.2$ to 10.2$)$ \\
$80-99$ & $16.2 \%(14.8$ to 17.6$)$ & $16.8 \%(15.8$ to 17.7$)$ \\
\hline $100-139$ & $25.8 \%(24.0$ to 27.6$)$ & $25.9 \%(24.5$ to 27.2$)$ \\
$140-179$ & $17.8 \%(16.4$ to 19.2$)$ & $17.5 \%(16.6$ to 18.4$)$ \\
\hline $800+$ & $31.2 \%(28.6$ to 33.7$)$ & $30.7 \%(28.6$ to 32.7$)$
\end{tabular}

Continued 
Disaster subsample, $\mathrm{n}=38981$

$(95 \% \mathrm{Cl})$
Full household sample, $\mathrm{n}=385127$

(95\% Cl)

\begin{tabular}{lcc}
\hline Primary occupation & & \\
\hline Agriculture & $6.4 \%(5.8$ to 6.9$)$ & $6.3 \%(5.8$ to 6.8$)$ \\
\hline Business & $5.9 \%(5.5$ to 6.2$)$ & $5.8 \%(5.6$ to 6.0$)$ \\
\hline Student & $27.9 \%(27.4$ to 28.5$)$ & $27.5 \%(27.2$ to 27.9$)$ \\
\hline Domestic work & $28.5 \%(28.1$ to 28.8$)$ & $28.6 \%(28.4$ to 28.9$)$ \\
Service & $3.7 \%(3.4$ to 4.1$)$ & $3.9 \%(3.7$ to 4.2$)$ \\
Not working & $3.2 \%(2.9$ to 3.5$)$ & $3.3 \%(3.1$ to 3.5$)$ \\
Skilled & $3.8 \%(3.5$ to 4.0$)$ & $3.7 \%(3.5$ to 3.9$)$ \\
Unskilled & $6.8 \%(6.3$ to 7.3$)$ & $7.0 \%(6.5$ to 7.4$)$ \\
\hline Other & $13.8 \%(13.4$ to 14.3$)$ & $13.8 \%(13.6$ to 14.1$)$ \\
\hline
\end{tabular}

flooding to be the greatest threat, followed by cyclones/ big storms.

\section{Vulnerability and impact}

Respondents were asked which members of the population were most likely to be impacted by natural disasters. Age was considered to be an important factor with older people $(23 \%)$ and children $(19 \%)$ considered to be most susceptible. Poor socioeconomic status (21\%) was perceived to increase vulnerability to natural disasters. Occupations perceived to be most affected by the natural disaster were farming $(32 \%)$, labourer jobs $(31 \%)$ and fishing $(20 \%)$.

Drowning during disaster was the primary concern for $87 \%$ of respondents. Debt, livestock and crop loss were prevailing concerns among the majority of respondents (78\%), while just $10 \%$ of respondents considered health to be a priority issue during disaster.

\section{Risk and protective factors}

The survey asked two separate questions with respect to weather forecast and warning signals. Only $18 \%$ of the respondents reported having received any type of weather forecast information prior to the most recent natural disaster that they had experienced. The most frequent sources of weather forecast information mentioned were from television $(30 \%)$, alarm or loud speakers $(20 \%)$ and through friends, families or neighbours (18\%).

A high proportion of respondents $(70 \%)$ reported having received warning signals prior to the onset of natural disaster. Although almost all households (95\%) had at least one member who owned a mobile phone, the most common source of warning signal was television ( $45 \%)$ followed by warnings from local authorities $(21 \%)$ and volunteers $(21 \%)$.

The majority of respondents $(95 \%)$ reported their household roof to be made of tin and only $4 \%$ reported to have a concrete roof. Walls were made of tin for $85 \%$ of households and brick and plaster for $11 \%$ of the households.

\section{Disaster preparedness practices}

Among respondents who reported to have experienced a natural disaster, only $19 \%$ evacuated at the time of the event. Limited money followed by limited time was identified as the two most common barriers to disaster preparedness (data not shown). Of the $81 \%$ of respondents who reported not evacuating, $44 \%$ believed evacuation was not required, $38 \%$ believed an alternative shelter was not easily accessible, $25 \%$ did not evacuate due to concerns about the security of their property and $13 \%$ remained to protect livestock. Less than $5 \%$ of community members were aware of evacuation processes or safe evacuation points/places.

Among respondents who had experienced disaster, 22\% reported moving to an alternate shelter during the most recent event. All reported moves were self-initiated with no rescues required from residences. Cyclone shelters (54\%) were used most often used for evacuation followed by educational institutions $(23 \%)$, flood shelters $(13 \%)$, relative's homes $(9 \%)$ and community centres $(1 \%)$.

\section{Qualitative results}

Interviewee characteristics are presented in table 2. Four focus groups were conducted consisting of two male groups and two female groups, with characteristics presented in table 3 .

Four overarching themes emerged from the qualitative data: (1) perceptions and consequences of disaster; (2) insufficient support for the most vulnerable (economically, geographically and personal physical attributes); (3) community preparedness and practices and (4) barriers to disaster response and improving resilience. The four overarching themes were drawn together from key subthemes which are available in online supplementary file 4 , together with illustrative quotes.

\section{Perceptions of risk and consequences of disaster}

Community members perceived disasters not to be preventable and viewed disaster-related death as unavoidable, or to occur as a result of 'Allah's will'. There was 


\begin{tabular}{lllll} 
Table 2 & Characteristics of in-depth interview participants & \\
\hline P1 & Gender & Age range (years) & Occupation & Disaster-related role \\
P2 & M & $35-39$ & Assistant teacher at high school & $\begin{array}{l}\text { Opens the doors of the local cyclone centre } \\
\text { and escorts people inside }\end{array}$ \\
P3 & M & $30-34$ & Fisherman and shop owner & $\begin{array}{l}\text { Delivers disaster warning signal through mic } \\
\text { in village }\end{array}$ \\
P4 & M & $30-34$ & Agricultural worker & Not specified \\
P5 & F & $25-39$ & Fisherman and labourer & Member of village disaster committee \\
P6 & F & $35-39$ & $\begin{array}{l}\text { Assistant teacher at primary } \\
\text { school }\end{array}$ & $\begin{array}{l}\text { Opens the doors of the school building and } \\
\text { escorts people inside for shelter }\end{array}$ \\
& & Social worker & $\begin{array}{l}\text { Educates villagers on disaster preparedness, } \\
\text { assists in delivering warning signal, helps } \\
\text { vulnerable people evacuate households, } \\
\text { leads search parties }\end{array}$ \\
P7 & F & $25-29$ & $\begin{array}{l}\text { Vice president of village disaster committee } \\
\text { (administrative role) }\end{array}$ \\
\end{tabular}

some acknowledgement of the relationship between water-related disasters and climate uncertainty, which was attributed to the impact of pollution.

And why these happen, I cannot say. Allah wishesthat's why it happens brother. Everything happens when Allah wishes. (P2, M, fisherman and shop owner)

A major concern for community members was the consequences of disaster on agriculture, with erosion and loss of crops and livestock having devastating impacts on livelihood.

The storm destroyed all the crops. I don't know whether we will get any rice or not from the grain. (FGD3, F, housewives)

In particular, loss of livestock was a significant concern for farmers, and the need to protect livestock presented a major impediment to evacuation. Similarly, theft and looting were cited as both a consequence of disaster and an impediment to evacuation. In terms of health consequences, drowning and illness due to poor sanitation

\begin{tabular}{|c|c|c|c|c|}
\hline & Gender & $\begin{array}{l}\text { Age range } \\
\text { (years) }\end{array}$ & $\begin{array}{l}\mathrm{N} \text { in each } \\
\text { group }\end{array}$ & Occupation \\
\hline FGD1 & $M$ & $30-60$ & 6 & $\begin{array}{l}\text { Small business } \\
\text { owners, } \\
\text { fishermen } \\
\text { and shop } \\
\text { keepers }\end{array}$ \\
\hline FGD2 & M & Unknown & 6 & $\begin{array}{l}\text { Business men } \\
\text { and fishermen }\end{array}$ \\
\hline FGD3 & $F$ & $25-50$ & 6 & Housewives \\
\hline FGD4 & $\mathrm{F}$ & $25-50$ & 5 & Housewives \\
\hline
\end{tabular}

postdisaster were considered to be major contributors to disaster-related morbidity and mortality.

\section{Insufficient support for the most vulnerable}

Respondents frequently reported on the structural weakness of existing dwellings and their inability to withstand a disaster event. A number of personal characteristics were repeatedly associated with increased vulnerability to drowning. Many of these surrounded the notion of 'weakness'-an inability to move quickly, hold onto stationary objects when caught in flood waters, swim against currents, climb to safe areas above flood waters or carry belongings overhead when crossing flood waters. Many of characteristics were specific to women, with traditional clothing worn becoming heavy when wet or long hair becoming caught on objects preventing escape from flood waters.

Women are in risk because they wear many clothes and they have long hair. That hair might be untied and get stuck or twisted with anything else. They don't have that much strength. So they cannot free themselves. (FGD2, M, businessmen and fishermen)

Statements were made about the care a woman feels for her children making her a liability to the broader family. There were mentions that women were less able than men to maintain calm or plan rationally in high pressure situations.

\section{Community preparedness and practices}

Participants discussed a number of approaches to preparing their households prior to disaster. These included securing food and valuables in safe, waterproof storage places, reinforcing households with rope and tarp, and creating floatation devices for family members from empty plastic soft drink bottles in case of flooding.

We put poles to support the house so that it doesn't fall. We take a thick rope and tie up one end of that 
rope with the house and tie up the other end of rope with a big tree tightly, so that the house doesn't fall during cyclone. (FGD3, F, housewives)

A variety of sources were used to communicate warnings in community settings prior and during disasters. Not all community members owned a TV or radio, and as power is often lost during weather events, loudspeaker announcements in village settings were considered to be most the effective warning signal. These announcements appeared to be predominantly coordinated by non-governmental organisations (NGOs). Warning signals were either based on a 10-point scale which indicates event severity, or were a simple call for evacuation, directing community members towards cyclone shelters and other protected areas of the community. Community members interpreted warning signals in different ways, with individuals having different thresholds for deciding when evacuation was necessary. Previous warnings given for seemingly minor events caused many participants to be sceptical about the urgency of signals.

And another thing is people don't want to go. As long as possible they try to stay in their own place. If they have left their things in that place then they might have lost their things. People don't want to leave their resort in their entire life. That's why problem increases more and people get hurt more by drowning in water. (FGD1, M, small business owners)

Many drowning deaths were reported to be caused by people evacuating their households after not responding to early warnings. Despite this, evacuation was considered an inconvenience to community members due to difficulties with transporting less-mobile people and the looting that frequently occurs when households are left unattended. One participant reported thieves staging false disaster warning signals for an opportunity to rob empty households.

We stay at home because if we leave the house the things will be stolen. We have nothing else than these things of the house. That's why we try to stay at the houses long as we can. (P3, M, agricultural worker)

\section{Barriers to disaster response and improving resilience}

Although there were a number of approaches documented towards disaster preparedness, management and relief, many of these were considered to be unreliable or unsustainable. Many participants discussed disaster management education provided by NGOs in community settings. Although useful, these education programmes were reported to be sporadic and with varied content. A lack of resources limited the extent individuals were able implement the practices taught. Consequently, disaster preparedness was predominately managed by individual community members.

Government initiatives were primarily focused on protection at the time of disaster and relief postdisaster. A number of cyclone shelters had been built by government in community settings and were frequently used by the most vulnerable members of the community at the time of disaster. Despite this, cyclone shelters were reported to be difficult to access due to unsafe roads and long distances between shelters. Furthermore, shelters were reportedly overcrowded, with poor structural quality and were potentially unsafe places for women.

Suppose there are two cyclone centres in our area. Already cracks have been developed in one building. Moreover they become filled up with people at the time when signal is shown. (FGD2, M, business men and fishermen)

There was a clear lack of faith in governance, with many comments concerning unequal distribution of government relief postdisaster, driven by bribery and nepotism.

At that time [those] who could give money as bribe he got that house and money. But [those] who actually needed he did not get the house and money.

(FGD1, M, small business owners)

Government postdisaster relief was only available over short periods of time postevent and in some cases, was also provided sporadically by NGOs.

\section{DISCUSSION}

This study has highlighted the considerable challenges confronting communities in disaster prone regions of Bangladesh in the face of inadequate warning systems, poor understanding and uptake of evacuation measures and insufficient relief responses. Each of these challenges are heightened for populations in remote geographical areas and those who are economically deprived. The impacts of disaster presented a heavy burden to communities in terms of housing, economic losses and the threat of drowning and illness. Identifying these issues highlights areas of priority to address through interventions. Increasing commitment from government to address disaster risk was viewed as a crucial step towards reducing disaster-related devastation. As a result, further investigation into policy interventions to improve governance surrounding this issue is required. Further, the need for community to self-manage disaster risk was considered a priority. This study identified several community strengths that could be built on as part of a comprehensive disaster resilience plan that fosters this approach.

A major impediment identified to effective disaster preparedness was the efficacy of warning systems. Despite high levels of mobile phone penetration in Bangladesh, the majority of survey respondents did not receive warnings through this means and instead relied on television $(45 \%)$ and warnings from local authorities and volunteers $(21 \%)$. There was significant heterogeneity in understanding and heeding warning signals, which contributed to a reluctance for evacuation. Warning signal efficacy was impacted by loss of electricity during flooding and 
poor community confidence in warning systems. This is consistent with the Osti and Nakasu ${ }^{3}$ review of inadequate warning systems across 10 southern and eastern Asian countries during 21 fatal flood events. The authors reported flood warning systems to be unreliable and the content of warnings to be too technical for community members. Taken together, these findings have critical implications for future research relating to appropriate messaging and the use of mobile technology as an avenue for early warning with high coverage.

There is significant unmet community need for effective disaster response, which must be addressed to move towards ensuring disaster resilience rather than recovery. While communities demonstrated strength with self-reliance, a systems-level approach was required to support the development of disaster resilience. There is limited insight into the ongoing mental health effects of disaster and how this impacts community resilience in disaster prone regions. ${ }^{14}$ However, the present findings confirm previous research that indicates disaster has a traumatic impact on families and communities. This signifies the need for a mental health workforce that are competent in disaster-related trauma and are responsive to the community in terms of culture, traditions, language and local practices. ${ }^{15}$ Further research is critical to understanding the impact of psychological trauma, which women may be more affected by than men, on community disaster resilience

At the community level, there was considerable concern for preserving agriculture and ultimately livelihoods. Protecting livestock was cited as a major barrier to evacuation and a significant contributor to disaster vulnerability, with $78 \%$ of survey participants reporting prevailing concerns about debt, livestock and crop loss at the time of a disaster event. Individual and community-level factors were key contributors to vulnerability, in particular house construction, age and gender.

Women were perceived to be more vulnerable than men, which was consistent with previous research; ${ }^{916}$ however, in high income settings, men have a higher mortality attributed to flood related-drowning. ${ }^{17}$ This is indicative of the 'socially determined' role of women in many LMICs and is aligned with an emerging focus in disaster literature on the role of women and how this contributes to vulnerability. ${ }^{914}{ }^{16}$ In Bangladesh, this is related to the socioeconomic status of women, health status and perpetration of violence against women. ${ }^{16}$ A cross-sectional survey with mothers spanning two floods in Bangladesh in 2007 , reported $86 \%$ of women experienced intimate partner violence (physical, emotional, sexual and sustenance abuse) during a flood. ${ }^{18}$ This study also reported that both unintentional injury (cuts, falls, drowning, etc) and parental violence against children is increased during flooding disaster. ${ }^{18}$ Perpetration of parental violence (physical, emotional and sustenance abuse) against children was highest in low socioeconomic families, in families with household unemployment and among mothers; particularly mothers engaged in domestic work (not employed) and those experiencing intimate-partner violence, all of which related to the extreme survival pressure. While women are seen as vulnerable to disaster and disaster-related trauma, there is great opportunity to empower and educate women in disaster preparedness and management practices to promote community resilience. $^{14}$

Natural disasters have a number of long-term indirect impacts on vulnerable populations. Communities repeatedly exposed to disasters may experience forced migration, either to urban centres or onto other hazard prone land. ${ }^{19}$ This contributes to rising land pressure, rapid urbanisation and a breakdown of community and social structures which disproportionally affects the poorest members of the population, increasing marginalisation. ${ }^{20}$ A lack of stability and security establishes a poverty cycle ${ }^{21}$ and enhances existing issues surrounding gender and social inequality. ${ }^{22}$ The underage marriage and trafficking of young girls has been reported to increase following disaster as children lose their parents, parents are unable to afford education due to disaster repair costs, or as schools are destroyed during disaster, impacting social-determinants of health adversely. ${ }^{23}$

\section{Implication for practice}

Improve commitment from government

Given the population density and scarce resources in the context, greater investment in preparedness and education rather than management and recovery is needed in Bangladesh. Disaster management was primarily undertaken by the NGOs/multilaterals, which was reported to be inconsistent. There is a need for improved coordination between relevant government agencies and NGOs to (1) prevent overlap of interventions in certain areas and support areas/communities currently without any interventions; (2) ensure the interventions available are consistent and offered to a high standard; (3) ensure postdisaster aid is distributed using regulated processes to areas of most need and (4) ensure allocation of funding is fair and appropriate governance mechanisms in place for distribution of support. Indeed government investment is essential to obtaining resources to improve basic public infrastructure (roads, dams and river embankments), constructing protective infrastructure, such as cyclone shelters and for improving the availability of emergency medical care postdisaster. In Bangladesh, increased government ownership and coordination could see considerable gains; however, better engagement with stakeholders at the community and policy level is needed to ensure a community-owned approach to promoting disaster resilience.

\section{Build resilient communities by strenthening of local disaster risk managment capacity}

All initiatives implemented should focus on empowering communities to mitigate disaster risk locally. This will assist in the promotion of cost-effective, local approaches to disaster preparedness, such as homemade personal 
floatation devices made from community sourced and readily available materials. The findings report on how communities/society in rural Bangladesh have organised themselves to increase resilience and manage disasters more effectively.

Participants reported not using cyclone shelters; however, overcrowding of shelters was also reported as a deterrent. Community ownership with respect to consultation on shelter location, feasibility and usability of infrastructure to access shelters might address some of the mistrust in governance/disaster management. This may be aided by building and using community infrastructures such as schools or mosques as disaster shelters, which would be an efficient and acceptable use of resources. Finally, while the community reported poor access to health services generally, this was compounded during disasters when it was clear that the health systems were non-existent; the need for resilient health systems cannot be overstated.

Resilience will also depend on the capacity of disaster management practices to be adjusted in a timely manner, in response to changing community priorities and the changing local environment. There should be a focus on reducing internal community conflicts caused by the provision of external resources to promote cohesive, united, community-based response to disaster. This would be aided by formal disaster committees, which would be helpful not only as an entity but for understanding and addressing concerns on distribution of resources within the population; however, to be effective, this also needs to be monitored. The aim of these committees could be to prepare the local population for disaster and take leadership in assisting community members at the time of disaster. To be effective, committee members would need external training (provided by government and/or NGOs) at regular intervals on various aspects of disaster preparedness, rescue and relief. Importantly, these committees should consist of a diverse range of community members who are part of the committee at an equal rank, including women and the elderly. Furthermore, committees should be government resourced and be in regular contact with government agencies and NGOs operating locally.

\section{CONCLUSION}

This study has highlighted the challenges facing water-related disaster prone region of Bangladesh. The results confirm previous research that emphasise the vulnerability of communities in the face of inadequate warning systems and poorly coordinated disaster responses, particularly for vulnerable/disadvantaged sectors of the community including the elderly, women, low socioeconomic families and those whose livelihood is rooted in agriculture. This research calls for increased government investment in systems-level responses that empower communities and promote resilience. Further research can support this by addressing the systems-level challenges to promoting disaster resilience, and investigating how existing community strengths can be leveraged to implement locally owned solutions .

Acknowledgements The authors acknowledge the field staff employed through the Centre for Injury Prevention and Research, Bangladesh who conducted all quantitative and qualitative data collection. We acknowledge the copyright of Royal National Lifeboat Institution for the map, figure 1. Due copyright permissions have been taken for use of the map in this manuscript. The authors also acknowledge Ms Aliki Christou, for her contributions to manuscript preparation.

Collaborators Centre for Injury Prevention and Research, Bangladesh.

Contributors JJ, AR, KB and RI conceived the study and its design. AR, FKC and $\mathrm{KB}$ led the acquisition of study data. KB led the quantitative data analysis. PC, FKC and CL performed initial qualitative data analysis. AR, RI, JJ and KB led data interpretation. All authors contributed to manuscript writing critically, for important intellectual content.

Funding The study was funded by the Royal National Lifeboat Institution, conducted with the support of Mr Steve Wills (Head of International Programmes) and Mr Dan Ryan (International Research Manager). The corresponding author had full access to all the data in the study and had final responsibility for the decision to submit for publication. Royal National Lifeboat Institution funded the project with Centre for Injury Prevention and Research, Bangladesh as collaborators and The George Institute for Global Health as academic partners.

Competing interests None declared.

Patient consent for publication Obtained.

Ethics approval Ethical clearance for this study was obtained from the University of Sydney, Australia; and Ethical Review Committee - Centre for Injury Prevention and Research Bangladesh.

Provenance and peer review Not commissioned; externally peer reviewed.

Data sharing statement Requests for access to study data should be addressed to the corresponding author. Data will be made available to the scientific community with as few restrictions as feasible, while retaining exclusive use until the publication of major outputs.

Open access This is an open access article distributed in accordance with the Creative Commons Attribution Non Commercial (CC BY-NC 4.0) license, which permits others to distribute, remix, adapt, build upon this work non-commercially, and license their derivative works on different terms, provided the original work is properly cited, appropriate credit is given, any changes made indicated, and the use is non-commercial. See: http://creativecommons.org/licenses/by-nc/4.0/.

\section{REFERENCES}

1. United Nations Office for Disaster Risk Reduction. Economic losses, poverty \& disasters: 1998-2017. Geneva, Switzerland: UNISDR, 2017.

2. De Silva MMGT, Kawasaki A. Socioeconomic vulnerability to disaster risk: a case study of flood and drought impact in a rural Sri Lankan community. Ecological Economics 2018;152:131-40.

3. Osti R, Nakasu T. Lessons learned from southern and eastern Asian urban floods: from a local perspective. J Flood Risk Manag 2016;9:22-35.

4. Cash RA, Halder SR, Husain M, et al. Reducing the health effect of natural hazards in Bangladesh. Lancet 2013;382:2094-103.

5. Childs D, Gordy M, Gordon M. Implementation of the Hyogo Framework for Action: Summary of Reports 2007-2013. Geneva: United Nations Office for Disaster Risk Reduction.

6. UNISDR. Sendai Framework for Disaster Risk Reduction 2015-2030. Geneva: United Nations Office for Disaster and Risk Reduction, 2015.

7. Huq S. Climate change and Bangladesh. Science 2001;294:1617-17.

8. Maplecroft V. Climate Change and Environmental Risk Atlas (CCERA) 2015. https://maplecroft.com/portfolio/new-analysis/2014/10/29/ climate-change-and-lack-food-security-multiply-risks-conflict-andcivil-unrest-32-countries-maplecroft/ (Accessed 29 Nov 2017).

9. Cannon T. Gender and climate hazards in Bangladesh. Gender \& Development 2002;10:45-50.

10. Hossain MJ, Biswas A, Mashreky SR, et al. Epidemiology of adulthood drowning deaths in Bangladesh: Findings from a nationwide health and injury survey. F1000Res 2017;6:589. 
11. Henderson RH, Sundaresan T. Cluster sampling to assess immunization coverage: a review of experience with a simplified sampling method. Bull World Health Organ 1982;60:253.

12. Harris PA, Taylor R, Thielke R, et al. Research electronic data capture (REDCap)--a metadata-driven methodology and workflow process for providing translational research informatics support. J Biomed Inform 2009;42:377-81.

13. National Institute of Population Research Training Bangladesh, Mitra Associates, ICF International. Bangladesh Demographic and Health Survey 2014. Dhaka, Bangladesh: NIPORT, Mitra and Associates, and ICF International, 2016.

14. Islam MR, Ingham V, Hicks $\mathrm{J}$, et al. The changing role of women in resilience, recovery and economic development at the intersection of recurrent disaster: a case study from Sirajgang, Bangladesh. J Asian Afr Stud 2017;52:50-67.

15. Choudhury WA, Quraishi FA, Haque Z. Mental health and psychosocial aspects of disaster preparedness in Bangladesh. Int Rev Psychiatry 2006;18:529-35.

16. Azad AK, Hossain KM, Nasreen M. Flood-induced vulnerabilities and problems encountered by women in northern Bangladesh. Int $J$ Disaster Risk Reduct 2013;4:190-9.
17. Jonkman SN, Kelman I. An analysis of the causes and circumstances of flood disaster deaths. Disasters 2005;29:75-97.

18. Biswas A, Rahman A, Mashreky S, et al. Unintentional injuries and parental violence against children during flood: a study in rural Bangladesh. Rural Remote Health 2010;10:1199-99.

19. Benson C, Clay EJ. Developing countries and the economic impacts of natural disasters. Managing disaster risk in emerging economies 2000:11-21.

20. Noy I, duPont IVW. The long-term consequences of natural disasters - A summary of the literature, 2016.

21. Schipper L, Pelling M. Disaster risk, climate change and international development: scope for, and challenges to, integration. Disasters 2006;30:19-38.

22. Arora-Jonsson S. Virtue and vulnerability: discourses on women, gender and climate change. Global Environmental Change 2011;21:744-51.

23. Mudavanhu C. The impact of flood disasters on child education in Muzarabani District, Zimbabwe. Jàmbá: Journal of Disaster Risk Studies 2014;6. 